\title{
An Intelligent Decision Support System to Prevent and Control of Dengue
}

\author{
Daphne Lopez ${ }^{1}$, Gunasekaran Manogaran ${ }^{2 *}$, R. Varatharajan ${ }^{3}$, Kaja M. Abbas ${ }^{4}$ \\ ${ }^{1}$ School of Information Technology and Engineering, VIT University, Vellore, India \\ ${ }^{2}$ University of California, Davis, USA, * gunavit@gmail.com \\ ${ }^{3}$ Sri Ramanujar Engineering College, India \\ ${ }^{4}$ Department of Infectious Disease Epidemiology, London School of Hygiene and Tropical \\ Medicine, London, UK
}

\begin{abstract}
Demographic shifts, social behavior modification, and climate change enhance the risk of dengue outbreaks globally. The Government of India has developed prevention and control strategies for dengue fever. We propose an intelligent decision support system based on multi-criteria decision analysis to improve strategic decision making among various alternatives, such as vaccination, disease surveillance, vector control, improved sanitation and access to safe drinking water, strengthening public health activities, awareness creation, and improving nutrition for women and children. The proposed alternatives are selected based on people, space and time criteria, such as low temperature and heavy rain, high temperature and high humidity, rainfall and water accumulation, resources and facilities, sociocultural and sociodemographic variables. The selection of alternatives based on multiple criteria is a complex decision-making problem. Policy and decision makers use linguistic terms to give their opinions and perspectives. We used the fuzzy logic based VIKOR (VIsekriterijumska optimizacija i KOmpromisno Resenje) method to analyze the linguistic terms collected from policy and decision makers to rank the optimal alternatives based on multiple criteria.
\end{abstract}

Keywords: Fuzzy logic, VIKOR, dengue, multi-criteria decision analysis, infectious disease prevention and control

\section{Introduction}

Government and healthcare professionals manage dengue outbreaks using multiple prevention and control strategies (Manogaran et al. 2017a; Manogaran et al. 2017b; Manogaran et al. 2017c). Complex procedures and challenges are involved in the dengue control strategies (Manogaran et al. 2017d; Thota et al. 2018), and the selection of the optimal dengue prevention and control strategy depends on people, space and time. Medical providers and health care administrators endeavor to reduce the operational and maintenance costs for prevention and control of dengue fever (Varatharajan et al. 2017a; Varatharajan et al. 2017b; Varatharajan et al. 2017c). The expenditure and demand for healthcare are also increasing rapidly. Professionals and administrators from the healthcare and other industries 
are jointly conducting various healthcare delivery procedures with the aim to enable efficient disease control strategies using the limited resources (Manogaran et al. 2017e; D. Lopez et al. 2016). These considerations are used to develop a decision-making model based on multiple criteria and alternatives (Cromwell et al. 2015). The goal of Multi Criteria Decision Making (MCDM) models is to make an effective decision at various stages of healthcare planning, such as strategic, tactical and operational. In every complex decision-making problem, there could be an optimal solution though it is a challenging task to identify such a solution. In general, strategic decisions are determined by the administrators or top-level management to develop and sustain the organization. In addition, there are ambiguities in strategic decisions, potential synergies among various alternatives, and uncertainties in the overall outcome (Manogaran et al. 2016; Manogaran et al. 2017f). Once the strategic decisions are made, then the organization determines tactical and operational planning decisions. Strategic, tactical and operational planning are grouped as a taxonomy in healthcare planning (Figure 1) (Manogaran et al. 2018; Kumar et al. 2017; Lopez et al. 2017a). Disease prevention and control strategies comprise of various managerial functions such as facility planning, arrangement and decision making (Manogaran et al. 2017g; Lopez et al. 2016; Varatharajan et al. 2017d). The above-mentioned criteria are used in the decision-making model to make the decisions for improving the organization. Thus, multi criteria decision analysis (MCDA) is employed in various environments (Tromp et al. 2012; Ghandour et al. 2015; Dehe et al. 2015).

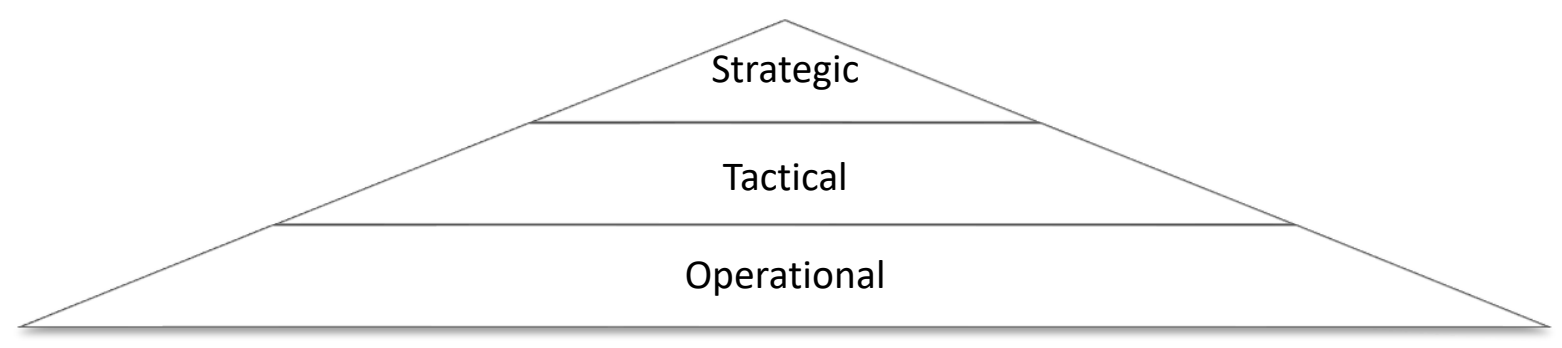

Figure 1. Taxonomy in healthcare planning.

\subsection{Strategic Planning in Healthcare}

Strategic planning is a long-term plan to achieve the overall goals and objectives of the organization (Frishammar 2003). In general, strategic planning consists of various administrative and organizational procedures to get the desired output (Varkey et al. 2010). Strategic planning in healthcare includes various factors such as designing an overall plan, identifying the goals, and getting approvals from the manager. For example, identifying the overall resource needs (hospitals, medical providers, drugs, and vehicles) and dimensioning the required resources (variety and specification of various resources) are some of the strategic plans in healthcare (Hulshof et al. 2012; Bradshaw et al. 2015).

\subsection{Tactical Planning in Healthcare}

Tactical planning refers to the overall steps that need to be followed to achieve the desired goals. The following questions are some of the examples of tactical planning in any 
organization i.e. where, what, which, how, who and when (Manogaran et al. 2017h). Tactical planning in healthcare is followed in two steps - Step 1: Identifying and classifying the individuals based on the disease and its severity and defining various required resources; Step 2: Collecting and installing the resources (hospitals, medical providers, drugs, and vehicles) that are identified in the strategic planning, and scheduling the workload, assigning tasks to all workers and scheduling them over time. Tactical planning in the healthcare industry includes staff shift scheduling and overtime scheduling in the surgical block (Gunduz et al. 2015). Tactical planning is also named as a blueprint of operational planning.

\subsection{Operational Planning in Healthcare}

Operational planning refers to the short-term goal of the organization. The primary purpose of the operational plan is to make a decision for desired healthcare delivery. Operational planning is also used to execute the steps that are identified in the tactical planning. In other words, blueprints are implemented at each resource level and individual patient level in the operational planning to get the desired output (Hulshof et al. 2012). In this paper, operational plan is done with the help of Fuzzy VIKOR Multi Criteria Decision Making (FMCDM). The proposed system provides various alternatives to prevent and control dengue fever. The proposed alternatives are selected based on people, space and time criteria, such as low temperature and heavy rain, high temperature and high humidity, rainfall and water accumulation, resources and facilities, sociocultural and sociodemographic variables. The above-mentioned criteria are used to identify the optimal alternative from the list of alternatives, such as vaccination, disease surveillance, vector control, improved sanitation and access to safe drinking water, strengthening public health activities, awareness creation, and improving nutrition for women and children.

\subsection{Dengue Surveillance}

Dengue fever is caused by Aedes aegypti and Aedes albopictus mosquitoes. Aedes aegypti mosquitoes breed in manmade products such as water tanks, tyres, pitchers, discarded containers, cement tanks, desert coolers and junk materials. Water stagnates in these places for several days, which enhances the breeding of these mosquitoes. Aedes aegypti is a day biting mosquito and breeds in dark areas such as inside the houses and storerooms (Manogaran et al. 2017i; Lopez et al. 2017b; Gandhi et al. 2018). Aedes albopictus mosquitoes breed in natural habitats such as gardens, inside grass, tree gaps and agricultural estates. Dengue disease burden is greater than before due to improper water storage methods, lack of awareness and rapid urbanization, and these root causes lead to increase in the mosquito breeding sites. Dengue cases are not uniformly distributed during the year, and they generally peak after the monsoon period. However, in the southern states of India, dengue burden is constant for all months, and in Gujarat the transmission is permanent. The major symptoms of dengue include fever, headache, rash, joint pains, muscle, nausea and vomiting (Rawal et al. 2017). 
Table 1. Midterm plan for dengue surveillance (National Vector Borne Disease Control Programme).

\begin{tabular}{|c|c|}
\hline Components & Description \\
\hline Surveillance & $\begin{array}{l}\text { Surveillance activities collect, analyze and generate reports from large volumes of data } \\
\text { from various sources. The results, guidelines and prevention strategies generated from the } \\
\text { surveillance system are used for prevention and control of diseases. }\end{array}$ \\
\hline Case management & $\begin{array}{l}\text { Case management is used to provide quality of care, laboratory diagnosis, desired } \\
\text { healthcare delivery, resource management and clinical management. Case management is } \\
\text { also used to enable efficient patient care services through various functions. They include } \\
\text { scheduling and planning, service monitoring, awareness creation, patient education service } \\
\text { and patient monitoring. }\end{array}$ \\
\hline $\begin{array}{l}\text { Vector } \\
\text { management }\end{array}$ & $\begin{array}{l}\text { Aedes aegypti and Aedes albopictus mosquitoes are the main vectors of chikungunya and } \\
\text { dengue fever in India. In order to control Aedes aegypti and Aedes albopictus mosquitoes, } \\
\text { effective vector control schemes are to be developed based on the knowledge of the vector } \\
\text { and its biology. Vector management is performed through environmental source } \\
\text { management, water storage management and drainage maintenance, personal protection } \\
\text { by protective clothing, chemical control and waste disposal management. }\end{array}$ \\
\hline Outbreak response & $\begin{array}{l}\text { Rapid emergency actions are needed to control and prevent dengue and chikungunya. } \\
\text { Outbreak responses are two types - the first one is an early diagnosis of diseases and } \\
\text { provide control strategies based on disease severity to prevent severe cases and deaths. } \\
\text { The second one is to provide emergency vector control guidelines to control transmission } \\
\text { of diseases. In addition, the following steps are also followed in outbreak response - } \\
\text { creating guidelines and sharing using media, verification of outbreak with current and } \\
\text { previous records, and perform lab tests such as blood sample collection, entomological } \\
\text { surveys and specimen analysis. }\end{array}$ \\
\hline Capacity building & $\begin{array}{l}\text { In order to share and implement the guidelines for prevention and control from dengue } \\
\text { requires trained professionals. It is required to conduct workshops, seminars and regional } \\
\text { meetings to strengthen the skills of individuals who are involving in the disease prevention } \\
\text { and control groups. Hands-on training sessions and simulation exercises should be given } \\
\text { to the medical force and skilled workers that would help to provide appropriate services to } \\
\text { the patients. Operational research should be performed at each region - it includes } \\
\text { analyzing space and time dynamics of dengue transmission, disease burden, and mapping } \\
\text { various vectors that are involved in space and time for dengue transmission. }\end{array}$ \\
\hline $\begin{array}{l}\text { Behavior change } \\
\text { communication }\end{array}$ & $\begin{array}{l}\text { Social mobilization and awareness creation are the major functions in controlling the } \\
\text { dengue outbreak. Social mobilization is used to involve individuals from not only the local } \\
\text { communities but also political leaders, VIPs and government officers. }\end{array}$ \\
\hline $\begin{array}{l}\text { Inter-sectoral } \\
\text { coordination }\end{array}$ & $\begin{array}{l}\text { In order to share the prevention and control strategies to the people, there is a need to } \\
\text { collaborate every health and non-health sector individuals. This collaboration is used to } \\
\text { enable resource sharing and policy adjustments between various individuals who are } \\
\text { working in the health and non-health sectors. }\end{array}$ \\
\hline $\begin{array}{l}\text { Monitoring and } \\
\text { supervision }\end{array}$ & $\begin{array}{l}\text { In order to control the outbreak of dengue, there is need to provide a robust surveillance } \\
\text { and monitoring system through entomological surveys and the resources to sustain the } \\
\text { surveillance system. Supervision is another task to control the dengue fever. Reports } \\
\text { generated from various locations, feedback collection, location visits, and review analysis } \\
\text { with current and previous disease cases are the major functions of supervision. }\end{array}$ \\
\hline
\end{tabular}


Dengue mortality rates can be minimized by surveillance and early detection of symptomatic infections. Government of India has developed various guidelines and prevention and control strategies that are circulated to every state in India. In addition, Indian Committee of Secretaries (CoS) have generated the midterm plan in May 2011 for prevention and control of dengue that are shared among the various states in India. The midterm plan consists of various guidelines and is also named as 'Octalogue', since it includes eight major components as depicted in Table 1 (NVBDCP 2018).

\subsection{Dengue Epidemiology}

Figure 2 illustrates the global burden of dengue in 2013, with 15.95 DALYs per 100,000 population (95\% UI: 10.15-27.61) (Institute for Health Metrics and Evaluation 2016). Like the confidence interval, the $95 \%$ uncertainty interval (UI) corresponds to the estimation related modeling uncertainties in the Global Burden of Disease (GBD) study (Murray et al. 2015), which includes uncertainties in data and estimates from other sources. DALYs combine the morbidity metric of Years of Life lost due to Disability (YLD) and mortality metric of Years of Life Lost due to premature mortality (YLL); that is, DALY = YLD + YLL. Figure 3 illustrates the burden of dengue in India from 1990 to 2013, with 11.1 DALYs per 100,000 population (95\% UI: 7.54-18.96) in 1990 increasing to 20.73 DALYs per 100,000 population [95\% UI: $11.28-40.24$ ] in 2013.

\subsection{Dengue in India}

In general, malaria and typhoid fevers were considered as emerging diseases in India. Chickungunya, dengue and leptospiral infections are also now considered in the re-emerging diseases group. The emerging and re-emerging diseases have a large health impact in India and cause major public health concerns. This paper analyses the health impact of dengue in India and proposes a framework for prevention and control of dengue. Dengue fever is caused by genus Flavivirus and Aedes. Aegypti mosquitoes transmit the genus Flavivirus to the individuals (Martina et al. 2009; Carey et al. 1966; Sarkar et al. 1964). People infected by dengue have the following symptoms at the severe stage such as circulatory failure, shock, coma and death (Bhattacharjee et al. 1993; Padbidri et al. 1996). The incidence of dengue was reported first in Chennai during 1780, thereafter it emerged all over India. Since the past few decades, there is a massive increase in dengue cases, and outbreaks have been reported from different states of India (Parida et al. 2002; Broor et al. 1997). World Health Organization (WHO) estimates the annual incidence of dengue infection to be around 50 million (Dar et al. 1999; WHO 2016b; Gupta et al. 2005).

Indian health officials report that in 2015, 84,391 dengue cases have been reported, while there were 40,571 and 4,117 cases in 2014 and 2013 respectively. The following states and union territories have experienced a large number of dengue cases compared to other states of India. It includes Delhi (15,531 cases), Punjab (12,628 cases) and Haryana (8,021 cases) (Herriman 2016). In Delhi, 158 cases reported were reported in 2014, while in 2015 the number of cases has increased to above 15,000 cases; this is the highest number of 


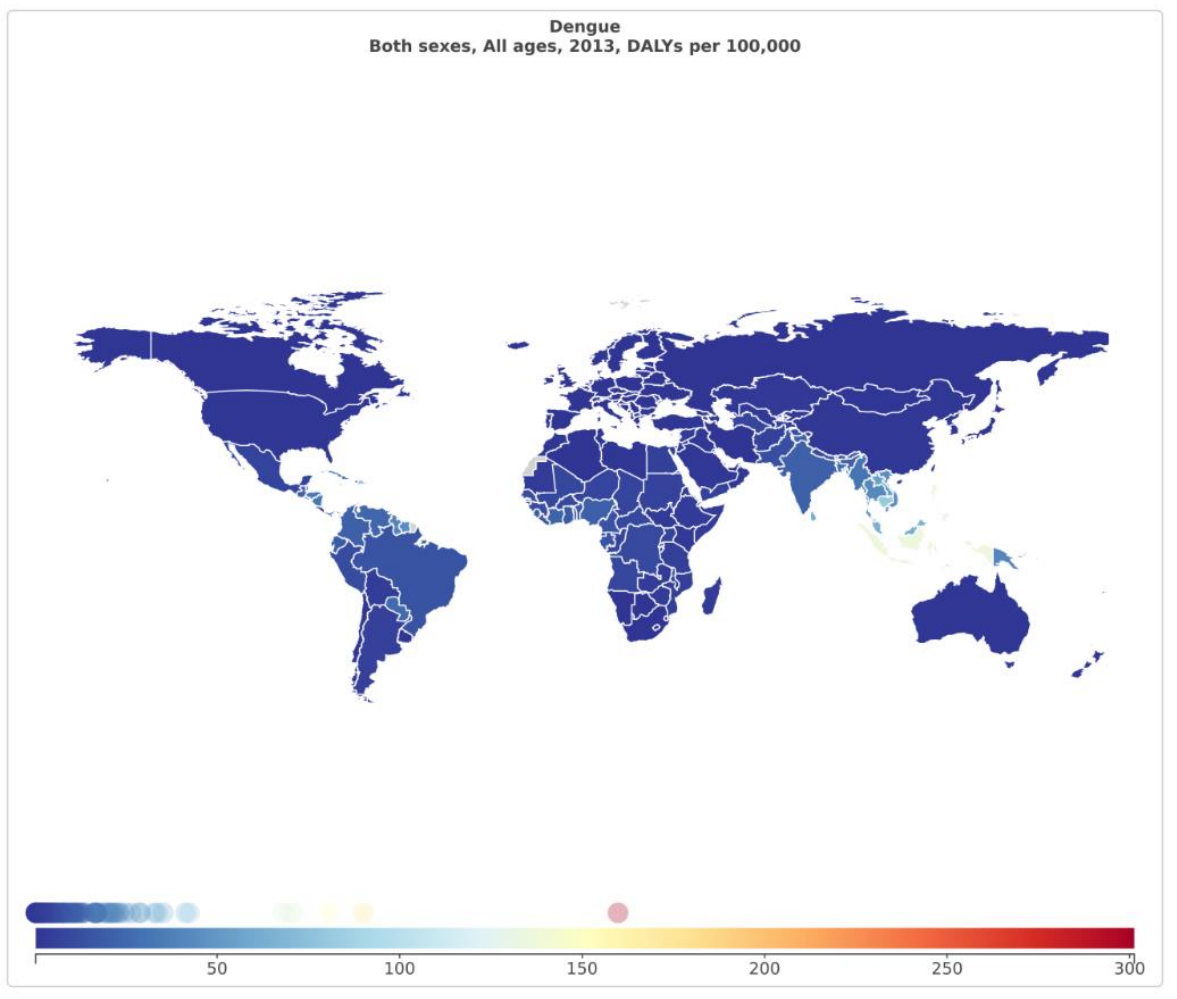

Figure 2. Global burden of dengue in 2013. Global burden of dengue in 2013 was 15.95 DALYs per 100,000 population [95\% UI: 10.15-27.61]. (Source: IHME)

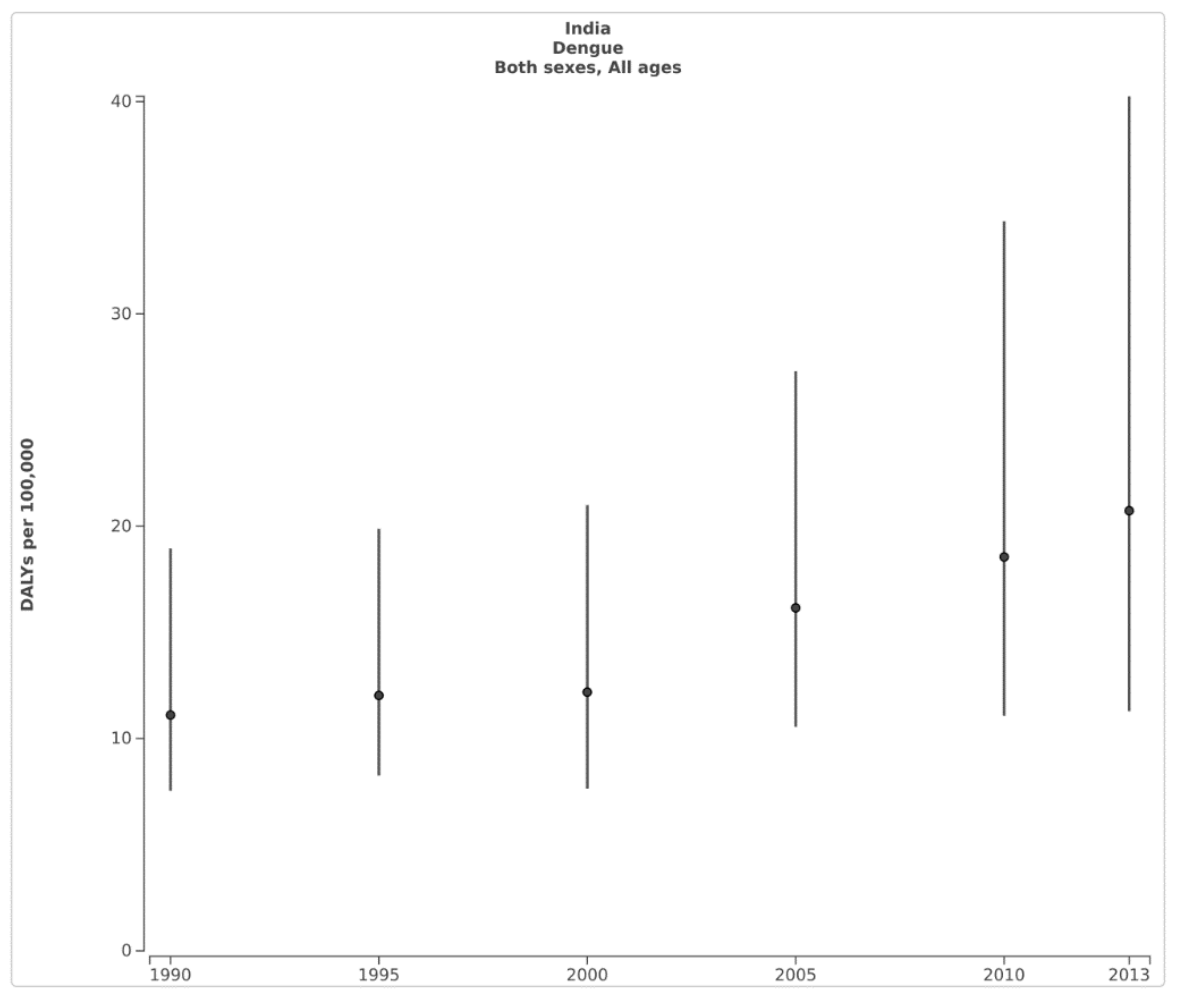

Figure 3. Burden of dengue in India from 1990 to 2013. Burden of dengue in India from 1990 to 2013, with 11.1 DALYs per 100,000 population [95\% UI: 7.54-18.96] in 1990 increasing to 20.73 DALYs per 100,000 population [95\% UI: 11.28-40.24] in 2013. (Source: IHME) 
dengue cases ever in Delhi since 1996 (Nath 2015). In September 2015 alone, dengue disease burden crossed 6,775 cases, and this is the highest number of reported cases since 2010 (India 2016). In the recent decade, 2010 was considered the deadliest year, with 4,375 cases. The worst dengue outbreak in Delhi was in 1996 with 10,252 cases and 423 deaths. In 2015, Punjab was affected by dengue with 13,731 cases and 18 deaths reported, while West Bengal and Haryana had 6,822 and 8,066 cases reported respectively. Tamil Nadu was affected by dengue with 128 cases and five deaths reported in 1998, while in 2003, 2005 and 2015, it increased to 1,600 cases and 12 deaths, 1,150 cases and 8 deaths, and 3,841 cases and 6 deaths respectively (Victor et al. 2007). In 2012, Tamil Nadu had a high number of 12,826 cases and 66 deaths (NVBDCP 2016),

The main reasons for dengue outbreaks include climate change and global warming, large population and population density, air and water pollution, land use change and rapid urbanization, and low awareness among the people. In order to control the dengue outbreaks, the Government of India has provided strategies to the public for prevention and control of dengue. In addition to that, this paper provides seven preventive strategies - vaccination, disease surveillance, vector control, improved sanitation and access to safe drinking water, strengthening public health activities, awareness creation, and improving nutrition for women and children. The proposed alternatives are selected based on people, space and time criteria, such as low temperature and heavy rain, high temperature and high humidity, rainfall and water accumulation, resources and facilities, and sociocultural and sociodemographic variables. In order to resolve uncertainties in the decision-making process and select the best alternative for prevention and control of dengue, this paper uses fuzzy logic based VIKOR method.

\subsection{Prevention and Control of Dengue}

The increasing burden of dengue in India necessitates improvement in prevention and control programs. Dengvaxia is a dengue vaccine that is licensed for use in 3 countries, including Mexico, Philippines and Brazil, it is not currently licensed for use in India (WHO 2016b). The prevention and control programs for dengue in India are awareness creation; improved nutrition for women and children; improved water, sanitation and hygiene; strengthening public health activities; surveillance; (potential) vaccination; and vector control. The different interventions have variances in epidemiological effectiveness, access and cost, and expert opinion of decision makers provide one viable option for public health decision making under uncertainty. Since there will be variances in the prioritization of interventions among the experts, we propose a fuzzy logic based VIKOR method to make objective decisions based on subjective opinions of the decision makers.

\subsection{Public Health Significance}

This study addresses the significant public health problem of making an objective decision based on subjective expert opinion of decision makers on dengue prevention and control in India. 


\section{Multi-Criteria Decision Making}

Multi-criteria decision making (MCDM) solves decision-making problems by using qualitative and quantitative evaluation criteria to select the optimal solution in complex environments (Bellman et al. 1970; Phuong et al. 2001). In the public health domain, MCDM models have been used to prevent and control emerging and reemerging diseases (De et al. 2001; Massad et al. 1999).

The following MCDM models have been used, including the Grey System Theory (GST), Goal Programming (GP), Analytic Network Process (ANP), Multi-Attribute Value Theory (MAVT), Analytic Hierarchy Process (AHP) and Data Envelopment Analysis (DEA). Saaty has developed AHP model to solve composite decision-making problems and are used to formulate a decision in contractor prequalification (Al-Harbi et al. 2001). Analytic Network Process (ANP) is similar to Analytic Hierarchy Process (AHP), but AHP forms a hierarchy with an end whereas ANP forms a network ( $\mathrm{Lu}$ et al. 2007). Data Envelopment Analysis (DEA) is used to monitor various functions of an organization. For example, DEA is used to schedule and monitor the bridge maintenance services (Ozbek et al. 2010). Technique for Order of Preference by Similarity to Ideal Solution (TOPSIS) is used to make a better decision based on the geometric distance between the events (Şimşek et al. 2013). Grey System Theory (GST) is developed based on differential equations to evaluate decisions. Hybrid decision making model is based on the above mentioned MCDM models (Jato-Espino et al. 2014).

Opricovic had developed VIKOR (VIsekriterijumska optimizacija iKOmpromisno Resenje) MCDM method to identify the optimal solution based on different criteria (Opricovic et al. 2007) by considering the variances in the preference values of different individuals involved in the decision-making process (Wang et al. 2009). Clinical diagnosis and epidemiological analysis have a high level of uncertainty and ambiguity (Broekhuizen et al. 2015, Lopez et al. 2015; Lopez et al. 2014), and decision-making models need to process and resolve this uncertainty. Fuzzy logic based VIKOR method is used in this paper to resolve uncertainties in decision making, with a focus on dengue prevention and control strategies.

\section{Fuzzy Logic}

\subsection{Fuzzy Set Theory}

\subsubsection{Fuzzy sets}

A fuzzy set is a set of objects and membership function valued between 0 and 1. Zadeh (1965) has introduced fuzzy set theory to assess real time fuzzy phenomenon problems that are vague, imprecise and unspecific (Zadeh et al. 1965). Fuzzy set theory is used to process subjective and imprecise judgments. Assume that $X$ be the universe of discourse, $X_{i}(i=$ $1,2, \ldots, n)$, a fuzzy set $\tilde{A}(x)$ is denoted by a membership function $\mu_{\tilde{A}}(x)$ (Zadeh et al. 1975). 


\subsubsection{Fuzzy numbers}

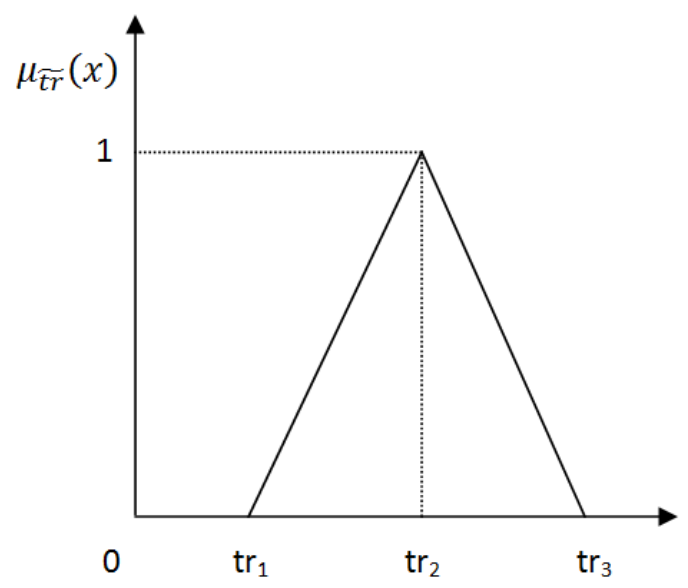

Figure 4. Triangular fuzzy number.

Fuzzy numbers are used to represent the linguistic variables, let a triangular fuzzy number $\widetilde{t r}$ be denoted as

$\widetilde{t r}=\left(t r_{1}, t r_{2}, t r_{3}\right)$

and its membership function $\mu_{\tilde{t} r}(x)$ (as shown in Figure 4) can be defined as (Liu et al. 2014):

$\mu_{\tilde{t r}}(x)=\left\{\begin{aligned} 0, & x<t r_{1}, \\ \frac{x-t r_{1}}{t r_{2}-t r_{1},}, & t r_{1} \leq x \leq t r_{2}, \\ \frac{t r_{3}-x}{t r_{3}-t r_{2}}, & t r_{2} \leq x \leq t r_{3}, \\ 0, & x>t r_{3},\end{aligned}\right.$

This paper focuses on alternatives for prevention and control of dengue based on various criteria. The decisions for each alternative are collected based on the following fuzzy linguistic variables. Triangular fuzzy number of $x$ is $\mu_{\overline{t r}}(x)$, where, $t r_{1} \leq t r_{2} \leq t r_{3}$

$t r_{1}=$ Least possible rate

$t r_{2}=$ More promising rate

$t r_{3}=$ Highest possible rate

Let $x_{i}$ and $y_{i}$ be two positive triangular fuzzy numbers $x_{i}(i=1,2,3), y_{i}(i=1,2,3)$ and a positive real number $p$, the arithmetical operations can be defined as follows:

$\tilde{x} \oplus \tilde{y}=\left[x_{1}+y_{1}, x_{2}+y_{2}, x_{3}+y_{3}\right]$

$\tilde{x} \ominus \tilde{y}=\left[x_{1}-y_{3}, x_{2}-y_{2}, x_{3}-y_{1}\right]$,

$\tilde{x} \otimes \tilde{y}=\left[x_{1} y_{1}, x_{2} y_{2}, x_{3} y_{3}\right]$

The operations of $\vee(\max )$ and $\wedge(\min )$ are defined as follows: 
$\tilde{x} \vee \tilde{y}=\left[x_{1} \vee y_{1}, x_{2} \vee y_{2}, x_{3} \vee y_{3}\right]$,

$\tilde{x} \wedge \tilde{y}=\left[x_{1} \wedge y_{1}, x_{2} \wedge y_{2}, x_{3} \wedge y_{3}\right]$

Scalar operations are defined as follows:

$r \oplus \tilde{x}=\left[r+x_{1}, r+x_{2}, r+x_{3}\right]$

$r \ominus \tilde{x}=\left[r-x_{1}, r-x_{2}, r-x_{3}\right]$

$r \otimes \tilde{x}=\left[r x_{1}, r x_{2}, r x_{3}\right]$

The Euclidean distance between two triangular fuzzy numbers $x_{i}(i=1,2,3), y_{i}(i=1,2,3)$ is defined as follows (Chen et al. 2008):

$D\left(X_{i}, Y_{i}\right)=\sqrt{\frac{1}{6}\left[\left(x_{1}-y_{1}\right)^{2}+4\left(x_{2}-y_{2}\right)^{2}+\left(x_{3}-y_{3}\right)^{2}\right]}$

The distance between the two triangular fuzzy numbers $x_{i}(i=1,2,3), y_{i}(i=1,2,3)$ by vertex method is defined as follows (Chen et al. 2000):

$D\left(X_{i}, Y_{i}\right)=\sqrt{\frac{1}{3}\left[\left(x_{1}-y_{1}\right)^{2}+\left(x_{2}-y_{2}\right)^{2}+\left(x_{3}-y_{3}\right)^{2}\right]}$

\subsubsection{Linguistic variables}

Linguistic terms such as low, medium and high are used to represent the linguistic variables. In general, linguistic variables are used to describe the imprecise or complex expressions. This paper uses fuzzy linguistic terms to rate criteria and rank the various dengue prevention and control strategies.

\section{Fuzzy VIKOR Multi-Criteria Decision Making}

VIKOR MCDM method is combined with fuzzy logic to solve various complex and ambiguous decision-making problems. In general, VIKOR method identifies two solutions best and compromise solutions to rate the alternatives in MCDM process.

Fuzzy logic based VIKOR method consists of the following steps to rank the alternatives (Figure 5):

Step 1: Identify the objective of the multi criteria decision making system.

Step 2: List the $p$ alternative methods called $A=\left\{A_{1}, A_{2}, \ldots, A_{P}\right\}$.

Step 3: List the $q$ selection criteria called $C=\left\{C_{1}, C_{2}, \ldots, C_{q}\right\}$. 
Step 4: List the $r$ decision-makers called $D M=\left\{D M_{1}, D M_{2}, \ldots, D M_{r}\right\}$ involved in the decision-making process to identify the optimal alternative from $p$ alternatives with respect to each $q$ criteria.

Step 5: Define the appropriate linguistic terms, fuzzy membership function $\mu_{\tilde{t}}(x)$ and triangular fuzzy number $\tilde{t}=\left(t_{1}, t_{2}, t_{3}\right)$ :

$\mu_{\tilde{t}}(x)=\left\{\begin{aligned} 0, & x<t 1, \\ \frac{x-t 1}{t 2-t 1}, & t 1 \leq x \leq t 2, \\ \frac{t 3-x}{t 3-t 2,}, & t 2 \leq x \leq t 3, \\ 0, & x>t 3,\end{aligned}\right.$

Step 6: Define the fuzzy criteria weights and collect the ratings for each alternative with respect to each criterion.

Step 7: Calculate the fuzzy decision matrix based on aggregated ratings of fuzzy alternatives and aggregated fuzzy weights of each criteria, let a set of fuzzy ratings of alternatives $A_{i}(i=1,2, \ldots, p)$ and criteria $C_{j}(j=1,2, \ldots, q)$, called $X=\left\{x_{i j}, i=1,2, \ldots, p, j=\right.$ $1,2, \ldots, q\}$.

Compute the normalized decision makers' fuzzy assessment of alternatives $\tilde{x}_{i j}^{k}=\left(\tilde{x}_{i j 1}^{k}, \tilde{x}_{i j 2}^{k}, \tilde{x}_{i j 3}^{k}\right)$ and aggregated fuzzy weights of criteria $\widetilde{w}_{i j}^{k}=\left(\tilde{x}_{i j 1}^{k}, \tilde{x}_{i j 2}^{k}, \tilde{x}_{i j 3}^{k}\right)$ :

$\tilde{x}_{i j}=\sum_{l=1}^{q} \vartheta_{1} \tilde{x}_{i j l}$

$\widetilde{w}_{j}=\sum_{l=1}^{q} \vartheta_{1} \widetilde{w}_{j l}$

Where $\vartheta_{1} \in[0,1]$ represents the weights given to the $l^{\text {th }}$ decision-maker, and $\sum_{l=1}^{q} \vartheta_{l}=1$.

The decision matrix $\widetilde{D}$ for dengue prevention and control programs is defined as:

$\widetilde{D}=\left[\begin{array}{cccc}\tilde{x}_{11} & \tilde{x}_{12} & \ldots & \tilde{x}_{1 q} \\ \tilde{x}_{21} & \tilde{x}_{22} & & \tilde{x}_{2 q} \\ \vdots & \vdots & \cdots & \vdots \\ \tilde{x}_{p 1} & \tilde{x}_{p 2} & \cdots & \tilde{x}_{p q}\end{array}\right], \widetilde{w}=\left(\widetilde{w}_{1}, \widetilde{w}_{2}, \ldots, \widetilde{w}_{q}\right)^{T}$

Step 8: Calculate the fuzzy best $\tilde{f}_{j}^{*}(i=1,2, \ldots, p)$ and fuzzy worst $\tilde{f}_{j}^{-}(j=1,2, \ldots, q)$ values from the aggregated fuzzy decision matrix $\tilde{x}_{i j}^{k}=\left(\tilde{x}_{i j 1}^{k}, \tilde{x}_{i j 2}^{k}, \tilde{x}_{i j 3}^{k}\right)$ :

$$
\begin{aligned}
& \tilde{f}_{j}^{*}=\left\{\begin{array}{cr}
\max _{i} \tilde{x}_{i j}, & \text { for benefit criteria } \\
\min _{i} \tilde{x}_{i j}, & \text { for cost criteria }
\end{array}\right\} \\
& \tilde{f}_{j}^{-}=\left\{\begin{array}{ll}
\min _{i} \tilde{x}_{i j}, & \text { for benefit criteria } \\
\max _{i} \tilde{x}_{i j}, & \text { for cost criteria }
\end{array}\right\}
\end{aligned}
$$




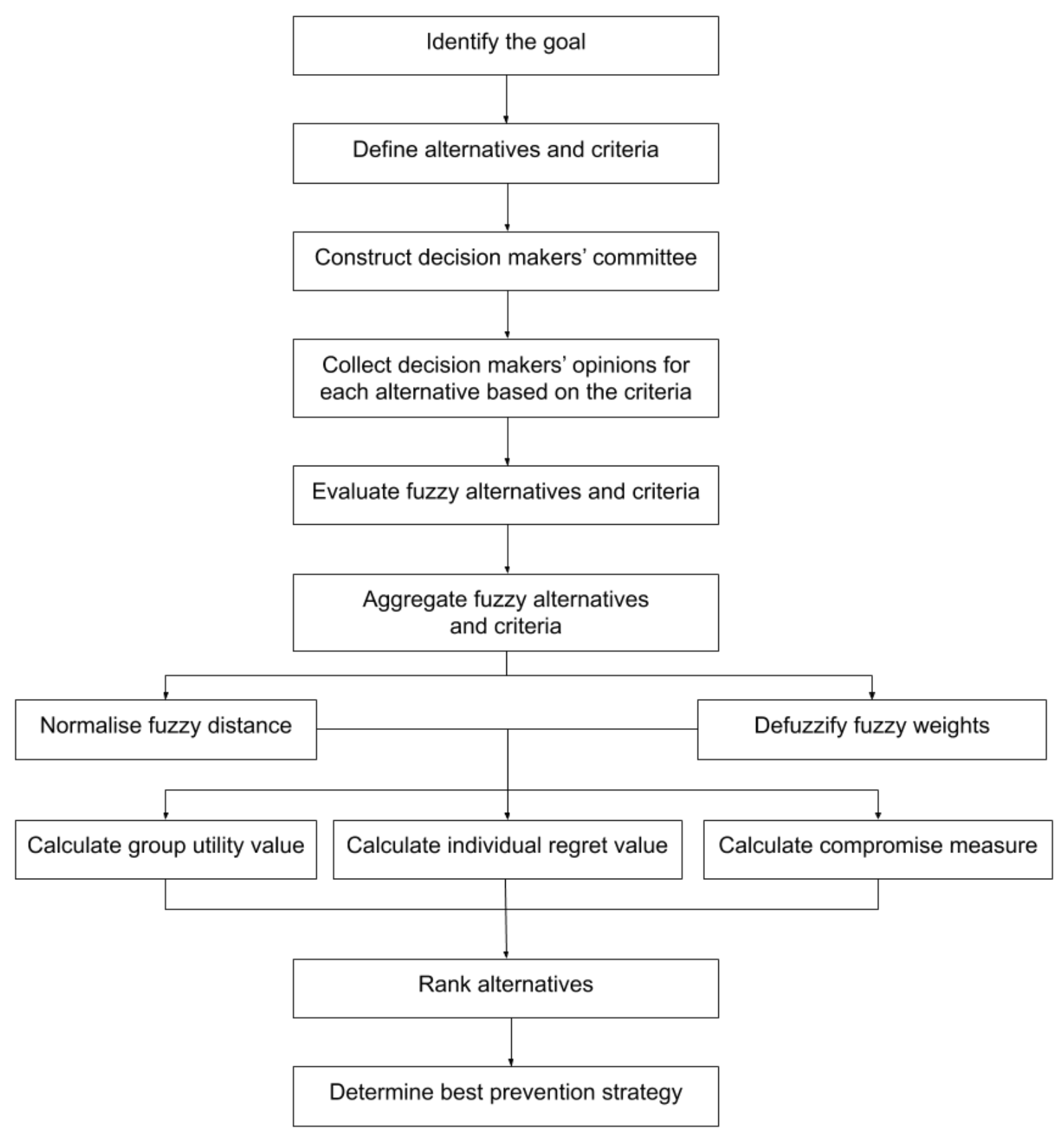

Figure 5. Representation of Fuzzy VIKOR Multi-Criteria Decision Making.

Step 9: Compute the average fuzzy distance values $\widetilde{d}_{i j},(i=1,2, \ldots, p, j=1,2, \ldots, q)$ from the aggregated fuzzy decision matrix $\tilde{x}_{i j}^{k}=\left(\tilde{x}_{i j 1}^{k}, \tilde{x}_{i j 2}^{k}, \tilde{x}_{i j 3}^{k}\right)$ :

$\bar{d}_{i j}=\frac{d\left(\tilde{f}_{j}^{*}, \tilde{x}_{i j}\right)}{d\left(\tilde{f}_{j}^{*}, \tilde{f}_{j}^{-}\right)}$

The Euclidean distance $D\left(X_{i}, Y_{i}\right)$ between any triangular fuzzy membership functions $A_{i}=$ $\left(X_{1}, X_{2}, X_{3}\right)$ and $Y_{i}=\left(Y_{1}, Y_{2}, Y_{3}\right)$ is calculated as follows: 
$D\left(X_{i}, Y_{i}\right)=\sqrt{\frac{1}{6}\left[\left(x_{1}-y_{1}\right)^{2}+4\left(x_{2}-y_{2}\right)^{2}+\left(x_{3}-y_{3}\right)^{2}\right]}$

Step 10: Fuzzy weights are defuzzified as $\bar{w}_{j}$ based on graded mean integration-based method:

$\bar{w}_{j}=\frac{\bar{w}_{j}+4 \times \bar{w}_{j}+\bar{w}_{j}}{6}, j=1,2, \ldots, q$

Step 11: Identify the group utility values $S_{i}$ and individual regret values $R_{i}, i=1,2, \ldots, p$, by the following equation:

$S_{i}=\sum_{j=1}^{n} \frac{\bar{w}_{j} \cdot \bar{d}_{i j}}{\sum_{j=1}^{n} \bar{w}_{j}}$

$R_{i}=\max _{j}\left(\frac{\bar{w}_{j} \cdot \bar{d}_{i j}}{\sum_{j=1}^{n} \bar{w}_{j}}\right)$

Step 12: The compromise measure $Q_{i}, i=1,2, \ldots, p$, can be defined as:

$Q_{i}=\vartheta \frac{S_{i}-S^{*}}{S^{-}-S^{*}}+(1-\vartheta) \frac{R_{i}-R^{*}}{R^{-}-R^{*}}$

Where $S^{*}=\min _{i} S_{i}, R^{*}=\min _{i} R_{i}, S^{-}=\max _{i} S_{i}, R^{-}=\max _{i} R_{i}$,

Let $\vartheta$ and $(1-\vartheta)$ be the weights for $S_{i}(i=1,2, \ldots, p)$ and $R_{i}(i=1,2, \ldots, p)$ respectively.

Let $\vartheta=0.5$ and $(1-\vartheta)=0.5$.

Step 13: List the various dengue prevention and control alternatives $A_{i}(i=1,2, \ldots, p)$ by sorting $S_{i}(i=1,2, \ldots, p), R_{i}(i=1,2, \ldots, p)$ and $Q_{i}(i=1,2, \ldots, p)$ in the decreasing order.

Step 14: Calculate the compromise measure if and only if the following two conditions are satisfied, otherwise go to Step 15.

Condition 1:

$Q\left(A^{(2)}\right)-Q\left(A^{(1)}\right) \geq \frac{1}{p-1}$

Condition 2:

$\left(A^{(1)}\right)$ Must be the first rank by $S_{i}$ and $R_{i}$.

Step 15: If Condition 1 is not satisfied, then the compromise measure can be calculated as follows:

$Q\left(A^{(N)}\right)-Q\left(A^{(1)}\right)<\frac{1}{p-1}$

Else if Condition 2 is not satisfied, then the compromise measures are alternatives $\left(A^{(1)}\right)$ and $\left(A^{(2)}\right)$. 


\section{Case Study: Assessment of Dengue Prevention Alternatives Selection Process}

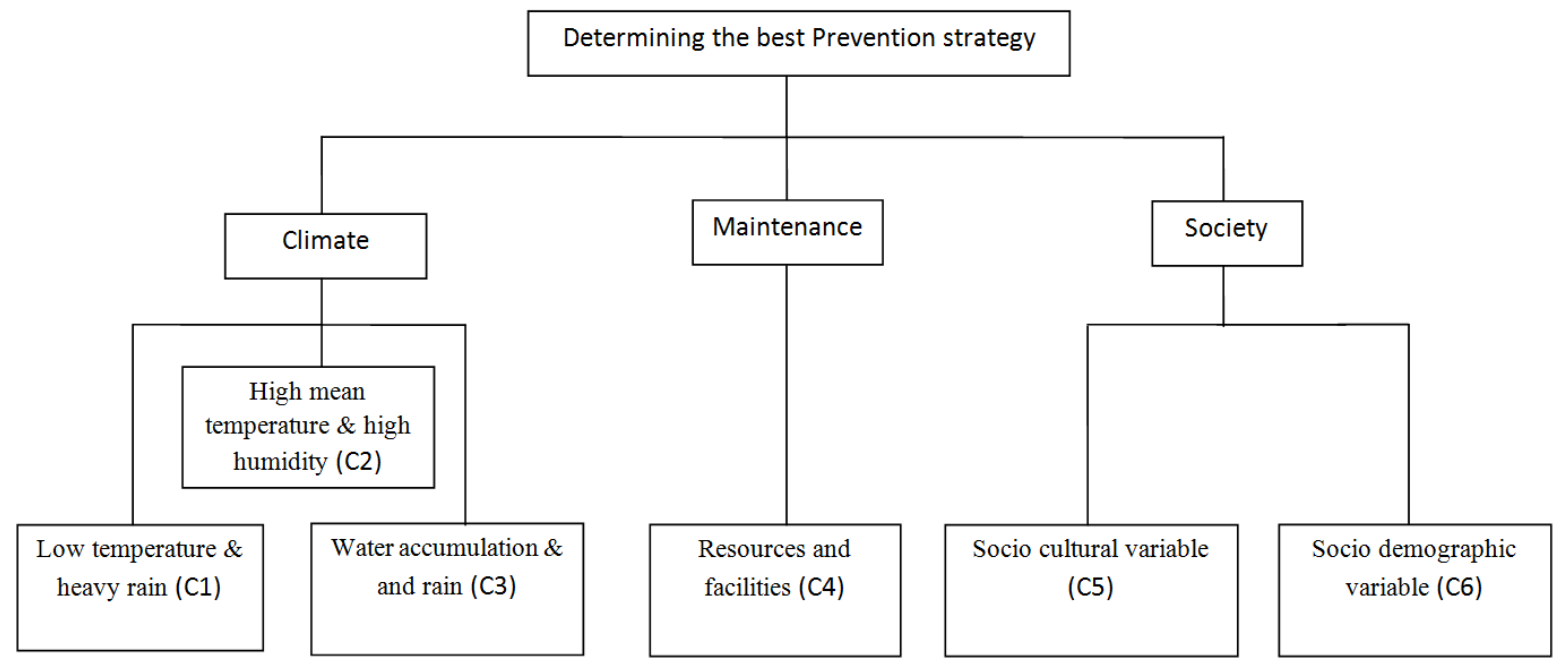

Figure 6. Hierarchical structure of the decision-making problem.

Step 1: The goal of this study is to select the best alternative for dengue prevention and control based on various criteria.

Step 2: Table 2 depicts the various alternatives for dengue prevention and control.

Table 2. Dengue prevention alternatives.

\begin{tabular}{|c|c|c|}
\hline Notation & Alternatives & Description \\
\hline $\mathrm{A}_{1}$ & Vaccination & $\begin{array}{l}\text { - Vaccination should be given to the age group of } 1.5 \text { years } \\
\text { to } 15 \text { years. } \\
\text { Dengue vaccination should be given in a } 3 \text {-dose series in } \\
\text { the month of January, June and December (Dengue Fever } \\
\text { Vaccine Program 2016). }\end{array}$ \\
\hline $\mathrm{A}_{2}$ & Disease surveillance & 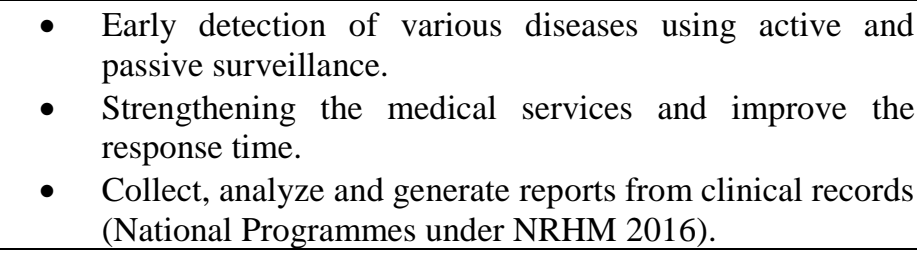 \\
\hline $\mathrm{A}_{3}$ & Vector control & $\begin{array}{l}\text { - Water storage management and drainage maintenance. } \\
\text { - Encourage to use protective clothes and Long-Lasting } \\
\text { Insecticidal Nets (LLINs). } \\
\text { - Encourage to use Indoor Residual Spraying (IRS) in hot } \\
\text { spot regions. } \\
\text { Environmental source reduction, identifying various } \\
\text { techniques for waste management. }\end{array}$ \\
\hline $\mathrm{A}_{4}$ & $\begin{array}{l}\text { Proper sanitation and } \\
\text { increased access to safe } \\
\text { drinking water }\end{array}$ & $\begin{array}{l}\text { - } \quad \text { Provide proper sanitation facilities. } \\
\text { - } \quad \text { Provide clean drinking water. } \\
\text { - } \quad \text { Proper maintenance of tube well. } \\
\text { - } \quad \text { Clean the water tank and water storage blocks regularly. }\end{array}$ \\
\hline $\mathrm{A}_{5}$ & $\begin{array}{l}\text { Strengthening public health } \\
\text { activities }\end{array}$ & $\begin{array}{l}\text { - Having safe food and water, as well as air quality. } \\
\text { - } \quad \text { Encourage to do physical exercise and yoga. }\end{array}$ \\
\hline $\mathrm{A}_{6}$ & Awareness creation & $\begin{array}{l}\text { - Establish more public activities to know more about } \\
\text { dengue outbreak. }\end{array}$ \\
\hline
\end{tabular}




\begin{tabular}{|c|l|l|}
\hline & $\begin{array}{l}\text { Use of electronic media and social networks such as } \\
\text { Twitter, Facebook and YouTube to create awareness of } \\
\text { dengue. }\end{array}$ \\
\hline \multirow{3}{*}{$\mathrm{A}_{7}$} & $\begin{array}{l}\text { Improving nutrition for } \\
\text { women and children }\end{array}$ & $\begin{array}{l}\text { Providing nutritional food for children and women. } \\
\text { Improving food safety, especially for child nutrition } \\
\text { products, to international standards. }\end{array}$ \\
& $\begin{array}{l}\text { Implementing new food safety law, and creating } \\
\text { awareness of food safety issues through schools, colleges, } \\
\text { women's groups and the social media. }\end{array}$ \\
\hline
\end{tabular}

Step 3: Six criteria (Table 3) are considered to select an efficient alternative for dengue prevention and control.

Table 3. Multiple criteria for decision making.

\begin{tabular}{|c|c|c|}
\hline Notation & Criteria & Description \\
\hline $\mathrm{C}_{1}$ & $\begin{array}{l}\text { Low temperature \& } \\
\text { heavy rain }\end{array}$ & $\begin{array}{l}\text { Most states with low temperature and heavy rain are } \\
\text { negatively correlated with the number of dengue cases } \\
\text { (Yang et al. 2009; Fouque et al. 2006; Tran et al. 2004). }\end{array}$ \\
\hline $\mathrm{C}_{2}$ & $\begin{array}{l}\text { High temperature \& } \\
\text { high humidity }\end{array}$ & $\begin{array}{l}\text { - High mean temperature and high humidity are positively } \\
\text { correlated with the number of dengue cases (Ehelepola } \\
\text { 2015). }\end{array}$ \\
\hline $\mathrm{C}_{3}$ & $\begin{array}{l}\text { Rainfall \& water } \\
\text { accumulation }\end{array}$ & $\begin{array}{l}\text { - Maintenance process involved in lakes and rivers. } \\
\text { - Maintenance process involved in water tank during winter } \\
\text { season. }\end{array}$ \\
\hline $\mathrm{C}_{4}$ & Resources \& facilities & $\begin{array}{l}\text { - Infrastructure: Lab, hospitals and in-patient beds. } \\
\text { - Transport: Ambulance and other vehicles. } \\
\text { - } \quad \text { Unilled personnel: Doctors and nurses. } \\
\text { - Workilled personnel: Compounders and wipers. } \\
\text { drugs, staff commitment and other costs for various } \\
\text { purposes. } \\
\text { - Communication and maintenance cost: Survey collection } \\
\text { about individuals' health history, lifestyle, vaccination } \\
\text { history, social behaviors, and preparing schedule for } \\
\text { vaccination and medical tests. }\end{array}$ \\
\hline $\mathrm{C}_{5}$ & Sociocultural variables & $\begin{array}{l}\text { Considering dress habits and lifestyle, for example, } \\
\text { improper clothing may increase probability of getting } \\
\text { dengue infection. } \\
\text { Considering daily travel plan, persons travelling more are } \\
\text { more likely to get dengue infection. }\end{array}$ \\
\hline $\mathrm{C}_{6}$ & $\begin{array}{l}\text { Sociodemographic } \\
\text { variables }\end{array}$ & $\begin{array}{l}\text { Considering social habits and lifestyle, for example, } \\
\text { people who are working in the drainage cleaning block are } \\
\text { more likely to get dengue infection (Neiderud 2015). } \\
\text { People who are working in urban places where the } \\
\text { hygienic levels are low are more likely to get dengue } \\
\text { infection. }\end{array}$ \\
\hline
\end{tabular}

Step 4: Different decision makers are identified to select the best prevention alternative from seven alternatives based on the above six criteria. In this study, five decision makers were selected as shown in Table 4, to select the best prevention strategy (Figure 6). 
Table 4. Decision makers.

\begin{tabular}{|c|l|}
\hline Decision Makers & Profession \\
\hline $\mathrm{DM}_{1}$ & Medical Officer from Women \& Child Development \\
\hline $\mathrm{DM}_{2}$ & Regional Officer from Health \& Family Welfare \\
\hline $\mathrm{DM}_{3}$ & Head Officer from Housing and Urban Poverty Alleviation \\
\hline $\mathrm{DM}_{4}$ & Director from Ministry of Health \& Family Welfare \\
\hline $\mathrm{DM}_{5}$ & Chief Officer from Ministry of Social Justice \& Empowerment \\
\hline
\end{tabular}

Step 5: Appropriate linguistic variables for each alternative (as shown in Figure 7) and criteria weights (as shown in Figure 8) are identified. The linguistic variables are depicted in Table 5 and Table 6 respectively.

Table 5. Fuzzy linguistic variables for rating the criteria weights.

\begin{tabular}{|l|l|}
\hline Linguistic Variables & Fuzzy Membership Function \\
\hline Very Low (VL) & $(0,0,0.25)$ \\
\hline Low $(\mathrm{L})$ & $(0,0.25,0.5)$ \\
\hline Medium $(\mathrm{M})$ & $(0.25,0.5,0.75)$ \\
\hline High $(\mathrm{H})$ & $(0.5,0.75,1)$ \\
\hline Very High $(\mathrm{VH})$ & $(0.75,1,1)$ \\
\hline
\end{tabular}

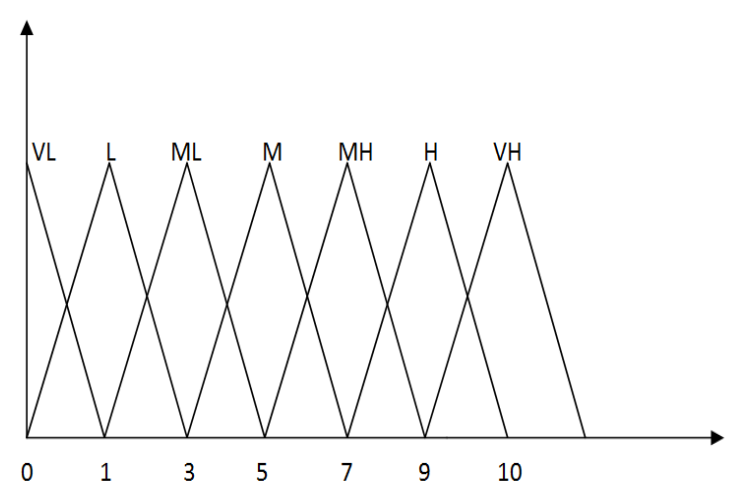

Figure 7. Fuzzy sets for alternative.

Table 6. Fuzzy linguistic variables for rating the alternatives.

\begin{tabular}{|l|l|}
\hline Linguistic Variable & Fuzzy Numbers \\
\hline Very Low (VL) & $(0,0,1)$ \\
\hline Low (L) & $(0,1,3)$ \\
\hline Medium Low (ML) & $(1,3,5)$ \\
\hline Medium (M) & $(3,5,7)$ \\
\hline Medium High (MH) & $(5,7,9)$ \\
\hline High $(\mathrm{H})$ & $(7,9,10)$ \\
\hline Very High $(\mathrm{VH})$ & $(9,10,10)$ \\
\hline
\end{tabular}




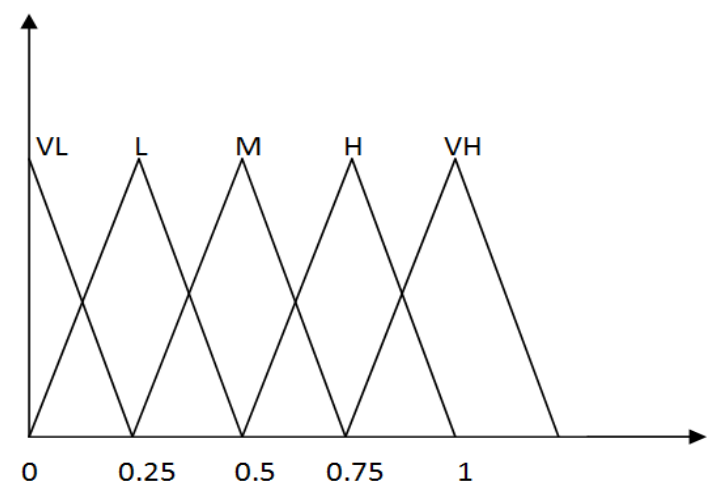

Figure 8. Fuzzy sets for criteria weights.

Step 6: Get the fuzzy logic-based values for all the alternatives with each criterion (Table 7) and linguistic weights for each criterion (Table 8).

Table 7. Decision makers' opinion in linguistic forms.

\begin{tabular}{|c|c|c|c|c|c|c|c|}
\hline \multirow{2}{*}{$\begin{array}{l}\text { Decision } \\
\text { Makers }\end{array}$} & \multirow[t]{2}{*}{ Alternatives } & \multicolumn{6}{|c|}{ Criteria } \\
\hline & & $\mathbf{C}_{1}$ & $\mathrm{C}_{2}$ & $\mathrm{C}_{3}$ & $\mathrm{C}_{4}$ & $\mathrm{C}_{5}$ & $\mathrm{C}_{6}$ \\
\hline \multirow[t]{7}{*}{$\mathrm{DM}_{1}$} & $\mathrm{~A}_{1}$ & $\mathrm{MH}$ & $\mathrm{H}$ & $\mathrm{H}$ & $\mathrm{VH}$ & $\mathrm{MH}$ & $\mathrm{MH}$ \\
\hline & $\mathrm{A}_{2}$ & $\mathrm{H}$ & MH & MH & $\mathrm{H}$ & $\mathrm{H}$ & MH \\
\hline & $\mathrm{A}_{3}$ & $\mathrm{VH}$ & $\mathrm{VH}$ & $\mathrm{VH}$ & $\mathrm{M}$ & $\mathrm{MH}$ & $\mathrm{H}$ \\
\hline & $\mathrm{A}_{4}$ & $\mathrm{H}$ & $\mathrm{MH}$ & $\mathrm{M}$ & $\mathrm{H}$ & $\mathrm{MH}$ & $\mathrm{H}$ \\
\hline & $\mathrm{A}_{5}$ & $\mathrm{VL}$ & $\mathrm{VL}$ & ML & $\mathrm{M}$ & $\mathrm{M}$ & ML \\
\hline & $\mathrm{A}_{6}$ & VL & VL & $\mathrm{L}$ & $\mathrm{L}$ & ML & $\mathrm{VL}$ \\
\hline & $\mathrm{A}_{7}$ & $\mathrm{M}$ & ML & $\mathrm{M}$ & ML & $\mathrm{MH}$ & $\mathrm{L}$ \\
\hline \multirow{7}{*}{$\mathrm{DM}_{2}$} & $\mathrm{~A}_{1}$ & M & $\mathrm{MH}$ & $\mathrm{MH}$ & $\mathrm{H}$ & $\mathrm{H}$ & $\mathrm{H}$ \\
\hline & $\mathrm{A}_{2}$ & $M$ & $\mathrm{MH}$ & $\mathrm{M}$ & $\mathrm{H}$ & $\mathrm{MH}$ & MH \\
\hline & $\mathrm{A}_{3}$ & $\mathrm{H}$ & VH & $\mathrm{H}$ & $\mathrm{MH}$ & $\mathrm{H}$ & $\mathrm{VH}$ \\
\hline & $\mathrm{A}_{4}$ & MH & $\mathrm{M}$ & $\mathrm{H}$ & $\mathrm{MH}$ & $\mathrm{M}$ & $\mathrm{MH}$ \\
\hline & $\mathrm{A}_{5}$ & $\mathrm{VL}$ & $\mathrm{L}$ & VL & ML & ML & VL \\
\hline & $\overline{A_{6}}$ & VL & VL & $\mathrm{L}$ & $\mathrm{L}$ & VL & VL \\
\hline & $\mathrm{A}_{7}$ & ML & ML & $\mathrm{M}$ & $\mathrm{MH}$ & $\mathrm{M}$ & $\mathrm{L}$ \\
\hline \multirow{8}{*}{$\mathrm{DM}_{3}$} & & & & & & & \\
\hline & $\mathrm{A}_{1}$ & ML & $\mathrm{H}$ & VH & $\mathrm{VH}$ & MH & $\mathrm{VH}$ \\
\hline & $\mathrm{A}_{2}$ & MH & MH & MH & $\mathrm{H}$ & MH & $\mathrm{M}$ \\
\hline & $\mathrm{A}_{3}$ & $\mathrm{H}$ & $\mathrm{VH}$ & $\mathrm{VH}$ & $\mathrm{MH}$ & $\mathrm{VH}$ & $\mathrm{VH}$ \\
\hline & $\mathrm{A}_{4}$ & $\mathrm{MH}$ & ML & $\mathrm{MH}$ & $\mathrm{M}$ & $\mathrm{M}$ & $\mathrm{MH}$ \\
\hline & $\mathrm{A}_{5}$ & ML & $\mathrm{VL}$ & ML & $\mathrm{L}$ & VL & ML \\
\hline & $\overline{A_{6}}$ & $\mathrm{~L}$ & ML & ML & $\mathrm{L}$ & VL & VL \\
\hline & $\mathrm{A}_{7}$ & ML & $\mathrm{M}$ & ML & $\mathrm{MH}$ & $\mathrm{MH}$ & $\mathrm{M}$ \\
\hline \multirow{5}{*}{$\mathrm{DM}_{4}$} & $A_{1}$ & $\mathrm{H}$ & $\mathrm{VH}$ & $\mathrm{H}$ & $\mathrm{VH}$ & $\mathrm{H}$ & $\mathrm{H}$ \\
\hline & $\mathrm{A}_{2}$ & MH & $\mathrm{MH}$ & $\mathrm{M}$ & $\mathrm{H}$ & $\mathrm{MH}$ & $\mathrm{M}$ \\
\hline & $\mathrm{A}_{3}$ & $\mathrm{VH}$ & VH & $\mathrm{MH}$ & $\mathrm{H}$ & MH & VH \\
\hline & $\mathrm{A}_{4}$ & $\mathrm{MH}$ & $\mathrm{H}$ & $\mathrm{M}$ & $\mathrm{M}$ & $\mathrm{MH}$ & ML \\
\hline & $\mathrm{A}_{5}$ & VL & VL & $\mathrm{L}$ & ML & VL & $\mathrm{L}$ \\
\hline
\end{tabular}




\begin{tabular}{|l|l|l|l|l|l|l|l|}
\hline & $\mathrm{A}_{6}$ & VL & L & VL & L & VL & VL \\
\hline & $\mathrm{A}_{7}$ & ML & ML & M & ML & M & M \\
\hline \multicolumn{7}{|l|}{} \\
\hline $\mathrm{DM}_{5}$ & $\mathrm{~A}_{1}$ & MH & VH & H & H & MH & MH \\
\hline & $\mathrm{A}_{2}$ & M & H & H & MH & M & M \\
\hline & $\mathrm{A}_{3}$ & VH & MH & VH & VH & MH & MH \\
\hline & $\mathrm{A}_{4}$ & MH & M & M & MH & MH & M \\
\hline & $\mathrm{A}_{5}$ & V $`$ & L & ML & ML & L & VL \\
\hline & $\mathrm{A}_{6}$ & L & VL & VL & L & VL & VL \\
\hline & $\mathrm{A}_{7}$ & ML & M & ML & ML & ML & ML \\
\hline
\end{tabular}

Table 8. Fuzzy rating of criteria weights.

\begin{tabular}{|c|l|l|l|l|l|l|}
\hline \multirow{2}{*}{$\begin{array}{c}\text { Decision } \\
\text { Makers }\end{array}$} & \multicolumn{7}{|c|}{ Criteria } \\
\cline { 2 - 7 } & $\mathbf{C}_{\mathbf{1}}$ & $\mathbf{C}_{\mathbf{2}}$ & $\mathbf{C}_{\mathbf{3}}$ & $\mathbf{C}_{\mathbf{4}}$ & $\mathbf{C}_{\mathbf{5}}$ & $\mathbf{C}_{\mathbf{6}}$ \\
\hline $\mathrm{DM}_{1}$ & $\mathrm{H}$ & $\mathrm{M}$ & $\mathrm{VH}$ & $\mathrm{M}$ & $\mathrm{L}$ & $\mathrm{H}$ \\
\hline $\mathrm{DM}_{2}$ & $\mathrm{VH}$ & $\mathrm{H}$ & $\mathrm{M}$ & $\mathrm{M}$ & $\mathrm{M}$ & $\mathrm{M}$ \\
\hline $\mathrm{DM}_{3}$ & $\mathrm{VH}$ & $\mathrm{H}$ & $\mathrm{M}$ & $\mathrm{L}$ & $\mathrm{L}$ & $\mathrm{H}$ \\
\hline $\mathrm{DM}_{4}$ & $\mathrm{H}$ & $\mathrm{H}$ & $\mathrm{H}$ & $\mathrm{M}$ & $\mathrm{M}$ & $\mathrm{L}$ \\
\hline $\mathrm{DM}_{5}$ & $\mathrm{H}$ & $\mathrm{M}$ & $\mathrm{H}$ & $\mathrm{H}$ & $\mathrm{M}$ & $\mathrm{M}$ \\
\hline
\end{tabular}

Step 7: Aggregated fuzzy logic-based alternatives $\tilde{x}_{i j}$ are calculated, and the results are shown in Table 9. Also, aggregated fuzzy logic-based weights $\widetilde{w}_{j}$ are calculated, and the results are depicted in Table 9. The following equations are used to calculate the values $\tilde{x}_{i j}$ and $\widetilde{w}_{j}$ respectively.

$\tilde{x}_{i j}=\sum_{l=1}^{q} \vartheta_{1} \tilde{x}_{i j l}$
$\widetilde{w}_{j}=\sum_{l=1}^{q} \vartheta_{1} \widetilde{w}_{j l}$

Table 9. Aggregated fuzzy logic-based alternatives and fuzzy ratings of criteria weights.

\begin{tabular}{|c|l|l|l|l|l|l|}
\hline \multirow{2}{*}{ Alternatives } & \multicolumn{7}{|c|}{ Criteria } \\
\cline { 2 - 7 } & $\mathbf{C}_{\mathbf{1}}$ & $\mathbf{C}_{\mathbf{2}}$ & $\mathbf{C}_{\mathbf{3}}$ & $\mathbf{C}_{\mathbf{4}}$ & $\mathbf{C}_{\mathbf{5}}$ & $\mathbf{C}_{\mathbf{6}}$ \\
\hline $\mathrm{A}_{1}$ & $(4.2,6.2,8)$ & $(7,8.8,9.8)$ & $(7,8.8,9.8)$ & $(7.8,9.2,9.8)$ & $(5.8,7.8,9.4)$ & $(6.6,8.4,9.6)$ \\
\hline $\mathrm{A}_{2}$ & $(4.6,6.6,8.4)$ & $(5.4,7.4,9.2)$ & $(4.6,6.6,8.4)$ & $(6.6,8.6,9.8)$ & $(5,7,8.8)$ & $(3.8,5.8,7.8)$ \\
\hline $\mathrm{A}_{3}$ & $(8.2,9.6,10)$ & $(8.2,9.4,9.8)$ & $(7.8,9.2,9.8)$ & $(5.8,7.6,9)$ & $(6.2,8,9.4)$ & $(7.8,9.2,9.8)$ \\
\hline $\mathrm{A}_{4}$ & $(5.4,7.4,9.2)$ & $(3.8,5.8,7.6)$ & $(4.2,6.2,8)$ & $(4.6,6.6,8.4)$ & $(4.2,6.2,8.2)$ & $(4.2,6.2,8)$ \\
\hline $\mathrm{A}_{5}$ & $(0.2,0.6,1.8)$ & $(0.0 .4,1.8)$ & $(0.6,2,3.8)$ & $(1.2,3,5)$ & $(0.8,1.8,3.4)$ & $(0.4,1.4,3)$ \\
\hline $\mathrm{A}_{6}$ & $(0,0.4,1.8)$ & $(0.2,0.8,2.2)$ & $(0.2,1,2.6)$ & $(0,1,3)$ & $(0.2,0.6,1.8)$ & $(0,0,1)$ \\
\hline $\mathrm{A}_{7}$ & $(1.4,3.4,5.4)$ & $(1.8,3.8,5.8)$ & $(2.2,4.2,6.2)$ & $(2.2,4.6,6.8)$ & $(3.4,5.4,7.4)$ & $(1.4,3,5)$ \\
\hline $\mathrm{W}$ & $(0.6,0.85,1)$ & $(0.4,0.65,0.9)$ & $(0.45,0.8,0.9)$ & $(0.25,0.5,0.75)$ & $(0.15,0.4,0.65)$ & $(0.3,0.55,0.8)$ \\
\hline
\end{tabular}

Step 8: Fuzzy best $\tilde{f}_{j}^{*}(j=1,2, \ldots, q)$ and fuzzy worst $\tilde{f}_{j}^{-}(j=1,2, \ldots, q)$ values are calculated based on the following equations $\tilde{f}_{j}^{*}$ and $\tilde{f}_{j}^{-}$respectively. 


$$
\begin{aligned}
& \tilde{f}_{j}^{*}=\left\{\begin{array}{lr}
\max _{i} \tilde{x}_{i j}, & \text { for benefit criteria } \\
\min _{i} \tilde{x}_{i j}, & \text { for cost criteria }
\end{array}\right\} \\
& \tilde{f}_{j}^{-}=\left\{\begin{array}{ll}
\min _{i} \tilde{x}_{i j}, & \text { for benefit criteria } \\
\max _{i} \tilde{x}_{i j}, & \text { for cost criteria }
\end{array}\right\}
\end{aligned}
$$

$\widetilde{f_{1}^{*}}=(0,0.4,1.8), \widetilde{f_{2}^{*}}=(0,0.4,1.8), \widetilde{f_{3}^{*}}=(0.2,1,2.6), \widetilde{f_{4}^{*}}=(0,1,3), \widetilde{f_{5}^{*}}=(0.2,0.6,1.8), \widetilde{f_{6}^{*}}=(0,0,1)$

$\widetilde{f_{1}^{-}}=(8.2,9.6,10), \widetilde{f_{2}^{-}}=(8 \cdot 2,9.4,9.8), \widetilde{f_{3}^{-}}=(7.8,9.2,9.8), \widetilde{f_{4}^{-}}=(7.8,9.2,9.8), \widetilde{f_{5}^{-}}=(6.2,8,9.4)$,

$\widetilde{f_{6}^{-}}=(27.8,9.2,9.8)$

Step 9: Aggregated fuzzy logic-based alternatives $\tilde{x}_{i j}$ are converted to normalized fuzzy logic-based distances $\tilde{d}_{i j}(i=1,2, \ldots, p ; j=1,2, \ldots, q)$ based on the following equations and the results are depicted in Table 10.

$$
\bar{d}_{i j}=\frac{d\left(\tilde{f}_{j}^{*}, \tilde{x}_{i j}\right)}{d\left(\tilde{f}_{j}^{*}, \tilde{f}_{j}^{-}\right)}
$$

The Euclidean distance $D\left(X_{i}, Y_{i}\right)$ between any triangular fuzzy membership functions $A_{i}=$ $\left(X_{1}, X_{2}, X_{3}\right)$ and $Y_{i}=\left(Y_{1}, Y_{2}, Y_{3}\right)$ are calculated based on the following equation:

$$
D\left(X_{i}, Y_{i}\right)=\sqrt{\frac{1}{6}\left[\left(x_{1}-y_{1}\right)^{2}+4\left(x_{2}-y_{2}\right)^{2}+\left(x_{3}-y_{3}\right)^{2}\right]}
$$

Step 10: Defuzzification of fuzzy weights $\bar{w}_{j}$ are calculated with help of graded mean integration method. The defuzzified crisp values $\bar{w}_{j}$ for each fuzzy weight are computed based on the following equation and the results are shown in the last row of Table 10.

$$
\bar{w}_{j}=\frac{\bar{w}_{j}+4 \times \bar{w}_{j}+\bar{w}_{j}}{6}, j=1,2, \ldots, q
$$

Table 10. Normalized fuzzy logic-based distances. Normalized fuzzy logic-based distances $\tilde{d}_{i j}$ for all alternatives $A=\left\{A_{1}, A_{2}, \ldots, A_{P}\right\}$ for each criteria $C=\left\{C_{1}, C_{2}, \ldots, C_{q}\right\}$ and crisp values of fuzzy weights $\bar{w}_{j}$.

\begin{tabular}{|c|l|l|l|l|l|l|}
\hline \multirow{2}{*}{ Alternatives } & \multicolumn{7}{|c|}{ Criteria } \\
\cline { 2 - 7 } & $\mathbf{C}_{\mathbf{1}}$ & $\mathbf{C}_{\mathbf{2}}$ & $\mathbf{C}_{\boldsymbol{3}}$ & $\mathbf{C}_{\mathbf{4}}$ & $\mathbf{C}_{\mathbf{5}}$ & $\mathbf{C}_{\mathbf{6}}$ \\
\hline $\mathrm{A}_{1}$ & 0.6348 & 0.9318 & 0.9497 & 1 & 0.9735 & 0.8232 \\
\hline $\mathrm{A}_{2}$ & 0.6796 & 0.7841 & 0.6865 & 0.9236 & 0.8683 & 0.6398 \\
\hline $\mathrm{A}_{3}$ & 1 & 1 & 1 & 0.8053 & 1 & 1 \\
\hline $\mathrm{A}_{4}$ & 0.7692 & 0.6015 & 0.4769 & 0.3661 & 0.7636 & 0.6798 \\
\hline $\mathrm{A}_{5}$ & 0.1825 & 0 & 0.1216 & 0.2387 & 0.1665 & 0.1586 \\
\hline $\mathrm{A}_{6}$ & 0 & 0.0386 & 0 & 0 & 0 & 0 \\
\hline $\mathrm{A}_{7}$ & 0.3287 & 0.3792 & 0.3911 & 0.4407 & 0.6539 & 0.3363 \\
\hline $\mathrm{W}$ & 0.8333 & 0.6666 & 0.7583 & 0.5 & 0.4 & 0.55 \\
\hline
\end{tabular}


Step 11: Group utility values $S_{i}(i=1,2, \ldots, p)$ are computed based on the following equation:

$$
S_{i}=\sum_{j=1}^{n} \frac{\bar{w}_{j} \cdot \bar{d}_{i j}}{\sum_{j=1}^{n} \bar{w}_{j}}
$$

Individual regret values $R_{i}(i=1,2, \ldots, p)$ are computed based on the following equation:

$R_{i}=\max _{j}\left(\frac{\bar{w}_{j} \cdot \bar{d}_{i j}}{\sum_{j=1}^{n} \bar{w}_{j}}\right)$

The results $S_{i}(i=1,2, \ldots, p)$ and $R_{i}(i=1,2, \ldots, p)$ are shown in Table 11 .

Step 12: Compromise measure $Q_{i}(i=1,2, \ldots, p)$ values are calculated based on the following equation and the results are shown in last row of Table 11.

$$
Q_{i}=\vartheta \frac{S_{i}-S^{*}}{S^{-}-S^{*}}+(1-\vartheta) \frac{R_{i}-R^{*}}{R^{-}-R^{*}}
$$

Where $S^{*}=\min _{i} S_{i}, S^{-}=\max _{i} S_{i}, R^{*}=\min _{i} R_{i}, R^{-}=\max _{i} R_{i}$,

Let $\vartheta$ and $(1-\vartheta)$ be the weights for $S_{i}(i=1,2, \ldots, p)$ and $R_{i}(i=1,2, \ldots, p)$ respectively. Let $\vartheta=0.5$ as threshold value and $(1-\vartheta)=0.5$

Table 11. Group Utility (S), Individual Regret (R) and Composite Measures (Q) for all alternatives.

\begin{tabular}{|c|l|l|l|l|l|l|l|}
\hline \multirow{2}{*}{ Criteria } & \multicolumn{7}{|c|}{ Alternatives } \\
\cline { 2 - 8 } & $\mathbf{A}_{\mathbf{1}}$ & $\mathbf{A}_{\mathbf{2}}$ & $\mathbf{A}_{\mathbf{3}}$ & $\mathbf{\mathbf { A } _ { 4 }}$ & $\mathbf{A}_{\mathbf{5}}$ & $\mathbf{A}_{\mathbf{6}}$ & $\mathbf{A}_{\mathbf{7}}$ \\
\hline $\mathrm{S}$ & 0.8663 & 0.7470 & 0.9737 & 0.6109 & 0.1395 & 0.0141 & 0.3972 \\
\hline $\mathrm{R}$ & 0.1941 & 0.1527 & 0.2247 & 0.1728 & 0.0409 & 0.0141 & 0.0799 \\
\hline $\mathrm{Q}$ & 0.8713 & 0.7108 & 1 & 0.6876 & 0.1289 & 0 & 0.3558 \\
\hline
\end{tabular}

Step 13: Group utility value $S_{i}(i=1,2, \ldots, p)$, individual regret value $R_{i}(i=1,2, \ldots, p)$ and compromise measure $Q_{i}(i=1,2, \ldots, p)$ are sorted in the decreasing order for all alternatives $A=\left\{A_{1}, A_{2}, \ldots, A_{P}\right\}$, and the results are shown in Table 12 .

Table 12. Group Utility (S), Individual Regret (R) and Composite Measures (Q) for all alternatives (ordered).

\begin{tabular}{|c|l|l|l|l|l|l|l|}
\hline \multirow{2}{*}{ Criteria } & \multicolumn{7}{|c|}{ Alternatives } \\
\cline { 2 - 9 } & $\mathbf{A}_{\mathbf{1}}$ & $\mathbf{A}_{\mathbf{2}}$ & $\mathbf{A}_{\mathbf{3}}$ & $\mathbf{A}_{\mathbf{4}}$ & $\mathbf{A}_{\mathbf{5}}$ & $\mathbf{A}_{\mathbf{6}}$ & $\mathbf{A}_{\mathbf{7}}$ \\
\hline $\mathrm{S}$ & 2 & 3 & 1 & 4 & 6 & 7 & 5 \\
\hline $\mathrm{R}$ & 2 & 4 & 1 & 3 & 6 & 7 & 5 \\
\hline $\mathrm{Q}$ & 2 & 3 & 1 & 4 & 6 & 7 & 5 \\
\hline
\end{tabular}

Step 14: Condition 1 and Condition 2 are satisfied; hence the compromise measure results $Q_{i}(i=1,2, \ldots, p)$ shows that vector control alternative $\left(\mathrm{A}_{3}\right)$ is the best alternative for dengue prevention and control. 


\section{Condition 1:}

$Q\left(A^{(2)}\right)-Q\left(A^{(1)}\right) \geq \frac{1}{p-1}$

where,

$\left(A^{(1)}\right)=$ Ranked $1^{\text {st }}$ by the compromise measure $Q_{i}$ (maximum) $(i=1,2, \ldots, p)$, which is $Q_{5}$

$\left(A^{(2)}\right)=$ Ranked $2^{\text {nd }}$ by the compromise measure $Q_{i}$ (maximum) $(i=1,2, \ldots, p)$, which is $Q_{7}$

$0.8713-1 \geq \frac{1}{7-1}$

$0.1287 \geq 0.1666$, Hence condition $\mathrm{C}_{1}$ is not satisfied.

Condition 2:

Alternative $\left(A^{(1)}\right)$ must be ranked first by $S_{i}$ and $R_{i}$.

$S^{\left(A_{3}\right)}>S^{\left(A_{1}\right)}>S^{\left(A_{2}\right)}>S^{\left(A_{4}\right)}>S^{\left(A_{7}\right)}>S^{\left(A_{5}\right)}>S^{\left(A_{6}\right)}$

$R^{\left(A_{3}\right)}>R^{\left(A_{1}\right)}>R^{\left(A_{4}\right)}>R^{\left(A_{2}\right)}>R^{\left(A_{7}\right)}>R^{\left(A_{5}\right)}>R^{\left(A_{6}\right)}$

Hence condition $\mathrm{C}_{2}$ is satisfied.

The sorted order of dengue prevention and control alternatives are depicted in Table 13.

Thus, the vector control strategy is the best method for dengue prevention and control.

Table 13. Ranking of alternatives for dengue prevention and control.

\begin{tabular}{|l|c|l|}
\hline Rank & Notation & Alternatives \\
\hline 1 & $\mathrm{~A}_{3}$ & Vector control \\
\hline 2 & $\mathrm{~A}_{1}$ & Vaccination \\
\hline 3 & $\mathrm{~A}_{2}$ & Disease surveillance \\
\hline 4 & $\mathrm{~A}_{4}$ & Proper sanitation and increased access to safe drinking water \\
\hline 5 & $\mathrm{~A}_{7}$ & Improving nutrition for women and children \\
\hline 6 & $\mathrm{~A}_{5}$ & Strengthening public health activities \\
\hline 7 & $\mathrm{~A}_{6}$ & Awareness creation \\
\hline
\end{tabular}

\section{Discussion}

\subsection{Public health implications}

This study illustrates the use of the fuzzy logic based VIKOR method for making an objective decision based on subjective decisions of experts and decision makers on prevention and control of dengue in India. 


\subsection{Public health decision making under uncertainty}

We have presented a solution for public health decision making under certainty, by using the fuzzy logic based VIKOR method for prioritization of interventions based on experts' opinion for dengue prevention and control. Dynamic modeling of dengue transmission dynamics provides another option for estimating the effectiveness and cost-effectiveness of different interventions, as done in the Disease Control Priorities (DCP-3) project to estimate efficacy and effectiveness of interventions for leading causes of global disease burden (DCP 2016).

\subsection{Limitations}

The limitation of this study is that the proposed model identifies the best alternative based on the input of five decision makers in a single setting. Future work can extend the decisionmaking framework for identification of best alternatives based on the inputs of different groups of decision-makers in varied settings.

\subsection{Conclusions}

Professionals and administrators from the healthcare and other industries are jointly designing healthcare strategies with the aim to enable efficient disease control programs using the available resources. To consider the individual preferences of various stakeholders, we have presented a multi-criteria decision-making framework. In the context of dengue, the prevention and control programs are vaccination, disease surveillance, vector control, improved sanitation and access to safe drinking water, strengthening public health activities, awareness creation, and improving nutrition for women and children. The proposed alternatives are selected based on people, space and time criteria, such as low temperature and heavy rain, high temperature and high humidity, rainfall and water accumulation, resources and facilities, sociocultural and sociodemographic variables. We used fuzzy logic based VIKOR method to analyze the linguistic terms collected from decision makers and ranked the best alternatives based on multiple criteria for selecting the optimal dengue prevention and control programs.

\section{References}

Al-Harbi, K. M. A. S. (2001). Application of the AHP in project management. International journal of project management, 19(1), 19-27.

Bellman, R. E., \& Zadeh, L. A. (1970). Decision-making in a fuzzy environment. Management science, 17(4), B-141.

Bhattacharjee, N., Mukherjee, K. K., Chakravarti, S. K., Mukherjee, M. K., De, P. N., Sengupta, M., ... \& Chakraborty, M. S. (1993). Dengue hemorrhagic fever (DHF) outbreak in Calcutta--1990. The Journal of communicable diseases, 25(1), 10-14.

Bradshaw, K., \& Urquhart, C. (2015). Theory and practice in strategic planning for health information systems.

Broekhuizen, H., Groothuis-Oudshoorn, C. G., Til, J. A., Hummel, J. M., \& IJzerman, M. J. (2015). A review and classification of approaches for dealing with uncertainty in multi- 
criteria decision analysis for healthcare decisions. Pharmacoeconomics, 33(5), 445455.

Broor, S., Dar, L., Sengupta, S., Chakaraborty, M., Wali, J. P., Biswas, A., ... \& Seth, P. (1997). Recent dengue epidemic in Delhi, India. Factors in the emergence of arbovirus diseases. Paris: Elsevier, 123-7.

Carey, D. E., Myers, R. M., Reuben, R., \& Rodrigues, F. M. (1966). Studies on dengue in Vellore, South India. American journal of tropical medicine and hygiene, 15(4), 58087.

Chen, C. T. (2000). Extensions of the TOPSIS for group decision-making under fuzzy environment. Fuzzy sets and systems, 114(1), 1-9

Chen, T. Y., Ku, T. C., \& Tsui, C. W. (2008). Determining attribute importance based on triangular and trapezoidal fuzzy numbers in (z) fuzzy measures. In The 19th International Conference on Multiple Criteria Decision Making (pp. 75-76).

Cromwell, I., Peacock, S. J., \& Mitton, C. (2015). 'Real-world' health care priority setting using explicit decision criteria: a systematic review of the literature. BMC health services research, 15(1), 1.

D. Lopez and G. Sekaran, "Climate change and disease dynamics - A big data perspective", International Journal of Infectious Diseases, vol. 45, pp. 23-24, 2016.

Dar, L., Broor, S., Sengupta, S., Xess, I., \& Seth, P. (1999). The first major outbreak of dengue hemorrhagic fever in Delhi, India. Emerging infectious diseases, 5(4), 589.

DCP. Disease Control Priorities. http://dcp-3.org/. (Accessed 15 August 2016)

De, S. K., Biswas, R., \& Roy, A. R. (2001). An application of intuitionistic fuzzy sets in medical diagnosis. Fuzzy sets and Systems, 117(2), 209-213.

Dehe, B., \& Bamford, D. (2015). Development, test and comparison of two Multiple Criteria Decision Analysis (MCDA) models: A case of healthcare infrastructure location. Expert Systems with Applications, 42(19), 6717-6727.

Dengue Fever Vaccine Program. (2016). Globalvaccines.org. Retrieved 16 September 2016, from http://www.globalvaccines.org/content/dengue+fever+vaccine+program/19615

Ehelepola, N. D. B., Ariyaratne, K., Buddhadasa, W. M. N. P., Ratnayake, S., \& Wickramasinghe, M. (2015). A study of the correlation between dengue and weather in Kandy City, Sri Lanka (2003-2012) and lessons learned. Infectious diseases of poverty, $4(1), 42$.

Fouque F, Carinci R, Gaborit P, Issaly J, Bicout DJ, et al. (2006) Aedes aegypti survival and dengue transmission patterns in French Guiana. J Vector Ecol 31: 390-399.

Frishammar, J. (2003). Information use in strategic decision making. Management Decision, 41(4), 318-326.

Gandhi, U. D., Kumar, P. M., Varatharajan, R., Manogaran, G., Sundarasekar, R., \& Kadu, S. (2018). HIoTPOT: Surveillance on IoT Devices against Recent Threats. Wireless Personal Communications, 1-16.

Ghandour, R., Shoaibi, A., Khatib, R., Rmeileh, N. A., Unal, B., Sözmen, K., ... \& Aissi, W. (2015). Priority setting for the prevention and control of cardiovascular diseases: multicriteria decision analysis in four eastern Mediterranean countries. International journal of public health, 60(1), 73-81.

Gunduz, H. I., Hempsch, C. K., \& Sebastian, H. J. (2015). Recent Advances in Strategic and Tactical Planning of Distribution Subnetworks for Letter Mail. In Quantitative Approaches in Logistics and Supply Chain Management (pp. 105-128). Springer International Publishing. 
Gupta, E., Dar, L., Narang, P., Srivastava, V. K., \& Broor, S. (2005). Serodiagnosis of dengue during an outbreak at a tertiary care hospital in Delhi. Indian Journal of Medical Research, 121(1), 36.

Herriman, R. (2016). India: Dengue cases double, malaria cases down in 2015 | Outbreak News Today. Outbreaknewstoday.com. Retrieved 16 September 2016, from http://outbreaknewstoday.com/india-dengue-cases-double-malaria-cases-down-in-20152015/

Hulshof, P. J., Kortbeek, N., Boucherie, R. J., Hans, E. W., \& Bakker, P. J. (2012). Taxonomic classification of planning decisions in health care: a structured review of the state of the art in OR/MS. Health systems, 1(2), 129-175.

India, P. (2016). Delhi Faces Worst Dengue Outbreak Since 1996. Over 12,000 Cases Reported. NDTV.com. Retrieved 16 September 2016, from http://www.ndtv.com/delhinews/delhi-faces-worst-dengue-outbreak-since-1996-over-12-000-cases-reported1232700

Institute for Health Metrics and Evaluation (IHME). GBD Compare. Seattle, WA: IHME, University of Washington, 2015. Available from http://vizhub.healthdata.org/gbdcompare. (Accessed 15 August 2016)

Jato-Espino, D., Castillo-Lopez, E., Rodriguez-Hernandez, J., \& Canteras-Jordana, J. C. (2014). A review of application of multi-criteria decision-making methods in construction. Automation in Construction, 45, 151-162.

Kumar, P. M., Gandhi, U., Varatharajan, R., Manogaran, G., Jidhesh, R., \& Vadivel, T. (2017). Intelligent face recognition and navigation system using neural learning for smart security in Internet of Things. Cluster Computing, 1-12.

Liu, H. C., You, J. X., You, X. Y., \& Shan, M. M. (2014). A novel approach for failure mode and effects analysis using combination weighting and fuzzy VIKOR method. Applied Soft Computing.

Lopez, D., \& Gunasekaran, M. (2015). Assessment of Vaccination Strategies Using Fuzzy Multi-criteria Decision Making. In Proceedings of the Fifth International Conference on Fuzzy and Neuro Computing (FANCCO-2015) (pp. 195-208). Springer International Publishing.

Lopez, D., \& Manogaran, G. (2016). Big Data Architecture for Climate Change and Disease Dynamics, Eds. Geetam S. Tomar et al. The Human Element of Big Data: Issues, Analytics,

Lopez, D., \& Manogaran, G. (2017a). Parametric Model to Predict H1N1 Influenza in Vellore District, Tamil Nadu, India. In Handbook of Statistics (Vol. 37, pp. 301-316). Elsevier.

Lopez, D., \& Manogaran, G., Jagan, J. (2017b). Modelling the H1N1 influenza using mathematical and neural network approaches, Biomedical Research, 28(8), 1-5.

Lopez, D., Gunasekaran, M., Murugan, B. S., Kaur, H., \& Abbas, K. M. (2014, October). Spatial big data analytics of influenza epidemic in Vellore, India. In Proceedings of the 2014 IEEE International Conference on Big Data (pp. 19-24). IEEE.

Lu, S. T., Lin, C. W., \& Ko, P. H. (2007, September). Application of analytic network process (ANP) in assessing construction risk of urban bridge project. In Second International Conference on Innovative Computing, Information and Control (ICICIC 2007).

Manogaran, G., \& Lopez, D. (2017b). Disease surveillance system for big climate data processing and dengue transmission. International Journal of Ambient Computing and Intelligence (IJACI), 8(2), 88-105. 
Manogaran, G., \& Lopez, D. (2017f). A survey of big data architectures and machine learning algorithms in healthcare. International Journal of Biomedical Engineering and Technology, 25(2-4), 182-211.

Manogaran, G., \& Lopez, D. (2017h). Spatial cumulative sum algorithm with big data analytics for climate change detection. Computers \& Electrical Engineering.

Manogaran, G., \& Lopez, D. (2017i). A Gaussian process based big data processing framework in cluster computing environment. Cluster Computing, 1-16.

Manogaran, G., \& Lopez, D., (2016). Health Data Analytics using Scalable Logistic Regression with Stochastic Gradient Descent. International Journal of Advanced Intelligence Paradigms, 9, 1-15.

Manogaran, G., Lopez, D., Thota, C., Abbas, K. M., Pyne, S., \& Sundarasekar, R. (2017c). Big data analytics in healthcare Internet of Things. In Innovative Healthcare Systems for the 21st Century (pp. 263-284). Springer International Publishing.

Manogaran, G., Thota, C., \& Lopez, D. (2018). Human-computer interaction with big data analytics. In HCI Challenges and Privacy Preservation in Big Data Security (pp. 1-22). IGI Global.

Manogaran, G., Thota, C., Lopez, D., Vijayakumar, V., Abbas, K. M., \& Sundarsekar, R. (2017a). Big Data Knowledge System in Healthcare. In Internet of Things and Big Data Technologies for Next Generation Healthcare (pp. 133-157). Springer International Publishing.

Manogaran, G., Varatharajan, R., \& Priyan, M. K. (2017g). Hybrid Recommendation System for Heart Disease Diagnosis based on Multiple Kernel Learning with Adaptive NeuroFuzzy Inference System. Multimedia Tools and Applications, 1-21.

Manogaran, G., Varatharajan, R., Lopez, D., Kumar, P. M., Sundarasekar, R., \& Thota, C. (2017d). A new architecture of Internet of Things and big data ecosystem for secured smart healthcare monitoring and alerting. Future Generation Computer Systems.

Manogaran, G., Vijayakumar, V., Varatharajan, R., Kumar, P. M., Sundarasekar, R., \& Hsu, C. H. (2017e) Machine Learning Based Big Data Processing Framework for Cancer Diagnosis Using Hidden Markov Model and GM Clustering. Wireless Personal Communications, 1-18.

Martina, B. E., Koraka, P., \& Osterhaus, A. D. (2009). Dengue virus pathogenesis: an integrated view. Clinical microbiology reviews, 22(4), 564-581.

Massad, E., Burattini, M. N., \& Ortega, N. R. (1999). Fuzzy logic and measles vaccination: designing a control strategy. International journal of epidemiology, 28(3), 550-557.

Murray CJL, Barber RM, Foreman KJ, et al. Global, regional, and national disability-adjusted lifeyears (DALYs) for 306 diseases and injuries and healthy life expectancy (HALE) for 188 countries, 1990-2013: quantifying the epidemiological transition. The Lancet 2015; 386: 2145-91.

Nath, D. (2015). Dengue cases: Delhi sets record in 20 years. The Hindu. Retrieved 16 September 2016, from http://www.thehindu.com/news/cities/Delhi/dengue-casescapital-sets-record-in-20-years/article7767767.ece

National Programmes under NRHM, Annual Report 2013-14, (2016). MOHFW. Retrieved 16 September 2016, from http://www.mohfw.nic.in/WriteReadData/1892s/Chapter615.pdf

Neiderud, C. J. (2015). How urbanization affects the epidemiology of emerging infectious diseases. Infection ecology \& epidemiology, 5(1), 27060.

NVBDCP | National Vector Borne Disease Control Programme. (2016). Nvbdcp.gov.in. Retrieved 16 September 2016, from http://nvbdcp.gov.in/den-cd.html

NVBDCP | National Vector Borne Disease Control Programme. (2018). Nvbdcp.gov.in. Retrieved 31 January 2018, from http://nvbdcp.gov.in/iec.html 
Opricovic, S., \& Tzeng, G. H. (2007). Extended VIKOR method in comparison with outranking methods. European journal of operational research, 178(2), 514-529.

Ozbek, M. E., de la Garza, J. M., \& Triantis, K. (2010). Efficiency measurement of bridge maintenance using data envelopment analysis. Journal of Infrastructure Systems, 16(1), 31-39.

Padbidri, V. S., Mahadev, P. V. M., Thakare, J. P., Pant, U., Ilkal, M. A., Varghese, G. G., ... $\&$ et Athavale, S. S. (1996). Virological and entomological investigations of an outbreak of dengue fever in Dhule district, Maharashtra. Indian Journal of Medical Microbiology, 14(1), 25.

Parida, M. M., Dash, P. K., Upadhyay, C., Saxena, P., \& Jana, A. M. (2002). Serological \& virological investigation of an outbreak of dengue fever in Gwalior, India. Indian journal of medical research, 116, 248.

Phuong, N. H., \& Kreinovich, V. (2001). Fuzzy logic and its applications in medicine. International journal of medical informatics, 62(2), 165-173.

Rawal, B. S., Vijayakumar, V., Manogaran, G., Varatharajan, R., \& Chilamkurti, N. (2018). Secure Disintegration Protocol for Privacy Preserving Cloud Storage. Wireless Personal Communications, 1-17.

Sarkar, J. K., Pavri, K. M., Chatterjee, S. N., Chakravarty, S. K., \& Anderson, C. R. (1964). Virological and Serological Studies of Cases of Haemorrhagic Fever in Calcutta. Material Collected by the Calcutta School of Tropical Medicine. The Indian journal of medical research, 52, 684.

Şimşek, B., İç, Y. T., \& Şimşek, E. H. (2013). A TOPSIS-based Taguchi optimization to determine optimal mixture proportions of the high strength self-compacting concrete. Chemometrics and Intelligent Laboratory Systems, 125, 18-32.

Thota, C., Sundarasekar, R., Manogaran, G., Varatharajan, R., \& Priyan, M. K. (2018). Centralized Fog Computing Security Platform for IoT and Cloud in Healthcare System. In Exploring the Convergence of Big Data and the Internet of Things (pp. 141-154). IGI Global.

Tran A, Deparis X, Dussart P, Morvan J, Rabarison P, et al. (2004) Dengue spatial and temporal patterns, French Guiana, 2001. Emerg Infect Dis 10: 615-621.

Tromp, N., \& Baltussen, R. (2012). Mapping of multiple criteria for priority setting of health interventions: an aid for decision makers. BMC health services research, 12(1), 1.

Varatharajan, R., Manogaran, G., \& Priyan, M. K. (2017c). A big data classification approach using LDA with an enhanced SVM method for ECG signals in cloud computing. Multimedia Tools and Applications, 1-21.

Varatharajan, R., Manogaran, G., Priyan, M. K., \& Sundarasekar, R. (2017b). Wearable sensor devices for early detection of Alzheimer disease using dynamic time warping algorithm. Cluster Computing, 1-10

Varatharajan, R., Manogaran, G., Priyan, M. K., Balaş, V. E., \& Barna, C. (2017d). Visual analysis of geospatial habitat suitability model based on inverse distance weighting with paired comparison analysis. Multimedia Tools and Applications, 1-21.

Varatharajan, R., Vasanth, K., Gunasekaran, M., Priyan, M., \& Gao, X. Z. (2017a). An adaptive decision based kriging interpolation algorithm for the removal of high density salt and pepper noise in images. Computers \& Electrical Engineering.

Varkey, P., \& Bennet, K. E. (2010). Practical techniques for strategic planning in health care organizations. Physician Executive Journal, 36(2), 46-48.

Victor, T. J., Malathi, M., Asokan, R., \& Padmanaban, P. (2007). Laboratory-based dengue fever surveillance in Tamil Nadu, India. Indian Journal of Medical Research, 126(2), 112. 
Wang, J., Xu, Y., \& Li, Z. (2009). Research on project selection system of pre-evaluation of engineering design project bidding. International Journal of Project Management, 27(6), 584-599.

WHO. (2016a). Who.int. Retrieved 16 September 2016, from http://www.who.int/tdr/publications

WHO. Questions and Answers on Dengue Vaccines. http://www.who.int/immunization/research/development/dengue_q_and_a/en/. (Accessed 15 August 2016b)

Yang HM, Macoris MLG, Galvani KC, Andrighetti MTM, Wanderley DMV (2009) Assessing the effects of temperature on the population of Aedes aegypti, the vector of dengue. Epidemiol Infect 137: 1188-1202.

Zadeh, L. A. (1965). Fuzzy sets. Information and control, 8(3), 338-353.

Zadeh, L. A. (1975). The concept of a linguistic variable and its application to approximate reasoning-II. Information sciences, 8(4), 301-357. 